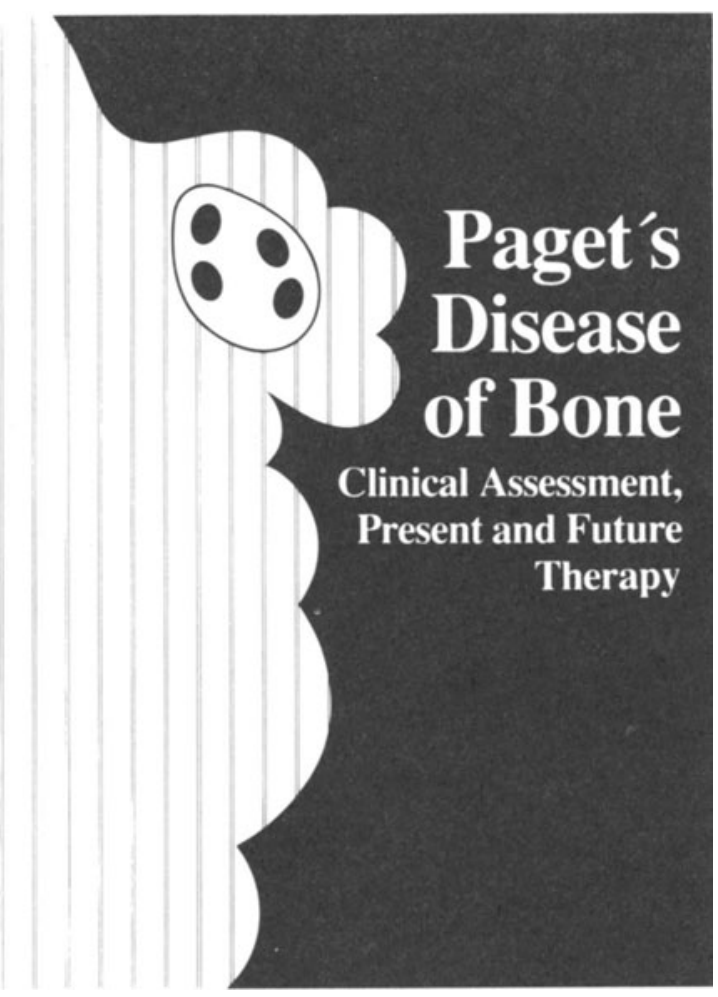


Design on preceding page: In 1877 Sir James Paget published his classic paper "On a form of chronic inflammation of the bones (osteitis deformans)."

Microscopic sketches of the bone pathology were prepared by Mr. H.T. Butlin and published in this paper. This design was adapted from Figure 10 drawn by $\mathrm{Mr}$. Butlin. The black represents bone with a scalloped border. The lined adjacent space represents the bone marrow. The multinucleated cell is an osteoclast, which has produced the resorbed surface of the bone. Thus this is a depiction of the earliest event in Paget's disease: increased bone resorption. 


\section{Paget's Disease of Bone}

\section{Clinical Assessment, Present and Future Therapy}

Proceedings of the Symposium on the Treatment of Paget's Disease of Bone, held October 20, 1989 in New York City

\section{Edited by}

\section{Frederick R. Singer, MD}

Professor of Medicine in Residence

UCLA School of Medicine

University of California at Los Angeles

Director, Bone Center

Cedars-Sinai Medical Center

Los Angeles, California

\section{Stanley Wallach, MD}

Professor and Associate Chairman

Department of Internal Medicine

University of South Florida College of Medicine

Tampa, Florida

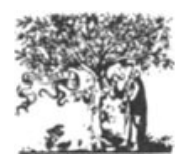

Elsevier

New York • Amsterdam $・$ London $・$ Tokyo 
No responsibility is assumed by the Publisher for any injury and/or damage to persons or property as a matter of products liability, negligence or otherwise, or from any use or operation of any methods, products, instructions, or ideas contained in the material herein. No suggested test or procedure should be carried out unless, in the reader's judgment, its risk is justified. Because of rapid advances in the medical sciences, we recommend that independent verification of diagnoses and drug dosages be made. Discussions, views, and recommendations as to medical procedures, choice of drugs, and drug dosages are the responsibility of the authors.

Elsevier Science Publishing Co., Inc.

655 Avenue of the Americas, New York, NY 10010

Sole distributors outside the United States of America and Canada:

Elsevier Science Publishers B.V.

P.O. Box 211, 1000 AE Amsterdam, The Netherlands

(c) 1991 by Elsevier Science Publishing Co., Inc.

Softcover reprint of the hardcover 1st edition 1991

This book has been registered with the Copyright Clearance Center, Inc.

For further information, please contact the Copyright Clearance Center, Inc.,

Salem, Massachusetts.

All inquiries regarding copyrighted material from this publication, other than reproduction through the Copyright Clearance Center, Inc., should be directed to: Rights and Permissions Department, Elsevier Science Publishing Co., Inc., 655 Avenue of the Americas, New York, New York 10010. FAX 212-633-3977.

This book is printed on acid-free paper.

Library of Congress Cataloging -in-Publication Data

Symposium on the Treatment of Paget's Disease of Bone (1989 : New York, N.Y.)

Paget's disease of bone : clinical assessment, present and future therapy : proceedings of the Symposium on the Treatment of Paget's Disease of Bone, held October 20, 1989 in New York City / edited by Frederick R. Singer, Stanley Wallach.

p. $\mathrm{cm}$.

Includes bibliographical references and indexes.

Includes index.

ISBN-13: 978-1-4684-2309-9 e-ISBN-13: 978-1-4684-2307-5

DOI: $10.1007 / 978-1-4684-2307-5$

1. Osteitis deformans-congresses. I. Singer, Frederick R., 1939-

II. Wallach, Stanley. III. Title.

[DNLM: 1. Osteitis Deformans-diagnostic-congresses. 2. Osteitis

Deformans-therapy-congresses. WE 2501989 S9886p]

RC931.065S96 1989

$616.7^{\prime} 12-\mathrm{dc} 20$

DNLM/DLC

for Library of Congress $\quad 91-16543$

Current printing (last digit):

10987654321

Manufactured in the United States of America 


\section{Contents}

Preface / ix

Acknowledgments / xiii

Contributors / xvii

\section{Chapter}

1 The Radiology of Paget's Disease / 1 Alex Norman, MD

\section{Chapter}

2 The Biochemistry of Paget's Disease / 20 Stephen M. Krane, MD

\section{Chapter}

3 The Pathology of Paget's Disease / 29

Steven L. Teitelbaum, MD

Chapter

4 Indications for Medical Treatment of Paget's Disease of Bone / 44

Ethel S. Siris, $M D$ 
Chapter

5 Experiences with Porcine and Salmon Calcitonin in the Treatment of Paget's Disease / 57

Stanley Wallach, MD

Chapter

6 Experiences with Human Calcitonin in the Treatment of Paget's Disease of Bone / 70

John G. Haddad, MD

Chapter

7 Resistance to Calcitonin / 75

Frederick $R$. Singer, $M D$ and

Karla Ginger, $B S$

Chapter

8 Treatment of Paget's Disease with Etidronate Disodium / 86 Pierre J. Meunier, MD and Alain Ravault, MD

Chapter

9 Disodium Pamidronate Therapy of Paget's Disease / 100 Olav L. M. Bijvoet, MD

Chapter

10 Treatment of Paget's Disease with the New Bisphosphonates / 112

John A. Kanis, MD, Eugene V. McCloskey, FRCP, Declan O'Doherty, FRCS, Neveen A. T. Hamdy, MD, Derek Bickerstaff, FRCS, Monique Beneton, BSc, and Maniccam Thavarajah, PhD

Chapter

11 Alternative Modes of Administration of Salmon Calcitonin in Paget's Disease of Bone / 135

Charles Nagant de Deuxchaisnes, MD and Jean-Pierre Devogelaer, MD

Chapter

12 Treatment of Paget's Disease with Short Courses of Bisphosphonates / 166

Peter Burckhardt, MD and

D. Thiébaud, $M D$

Chapter

13 Two Decades of Experiences in the Treatment of Paget's Disease of Bone with Plicamycin (Mithramycin) / 176 Will G. Ryan, MD 
Chapter

14 Arthritis and Paget's Disease of Bone / 191 Stephen M. Krane, MD and

Susan F. Kroop, MD

Chapter

15 Surgery in Paget's Disease / 200

Frederick S. Kaplan, MD

Annotated Bibliography / 215

Author Index / 304

Subject Index / 307

Index / 309 


\section{Preface}

Paget's disease is an old disease historically, but a new disease therapeutically. Human remains unearthed in Lancashire, England, dating from approximately $900 \mathrm{AD}$, show clear evidence of the affliction. However, it was not until the 1800 s that physicians rediscovered the condition, and a little more than 100 years ago that Sir James Paget published a perceptive and accurate description of the disease from the clinical and pathologic points of view. He felt the disease represented an inflammatory condition of the skeleton and hence named it osteitis deformans. The condition again lapsed into anonymity for several decades afterwards, and therapeutic approaches did not evolve until after World War II when several groups, located mainly in the Boston area, began using a variety of agents, including corticosteroids for treatment of this condition. These early attempts at therapy were unsuccessful and the condition remained essentially untreatable until the development of the calcitonins and the bisphosphonates in the 1970s.

In 1978, the Paget's Disease Foundation, a private nonprofit voluntary health agency, was founded to assist individuals afflicted by Paget's disease of bone, to provide education regarding this condition to the medical community, and to encourage research efforts to better understand and treat the condition. An international conference was organized under the aegis of the Paget's Disease Foundation and was held in New York City in October, 1989, ten years after the founding of the Paget's Disease Foundation. The purpose of the conference was to discuss the progress, within the previous ten years, of the clinical assessment of Paget's disease and to place in perspective the status of present therapy and the prospects for future therapy. This book is based on this international 
conference and details the latest information concerning the diagnosis and treatment of Paget's disease.

Fourteen internationally known authorities on Paget's disease participated in the conference and in the preparation of this unique volume. Dr. Stephen Krane, from Harvard Medical School, reviewed the biology and biochemistry of the condition and the biochemical parameters that can be used to characterize disease activity. Dr. Stephen Teitelbaum of Washington University School of Medicine reviewed the pathologic features of Paget's disease and discussed both the cellular and structural abnormalities characteristic of the disorder. Dr. Ethel Siris of Columbia University College of Physicians and Surgeons discussed the clinical signs and symptoms and indications for treatment, paying special attention to the management of bone pain, intercurrent orthopedic surgery, and complications such as hearing loss, disturbed mineral metabolism, and the deleterious effects of immobilization. Dr. Alex Norman of New York Medical College outlined the radiologic features, the use of radiologic techniques in diagnosis, and the radiologic features of Paget's disease complications, including fractures and secondary tumorogenesis. Dr. Stephen Krane also discussed arthritis management in Paget's disease. Dr. Frederick Kaplan of the University of Pennsylvania School of Medicine discussed the role of orthopedic surgery in the management of patients with complications.

The remainder of the conference was devoted to medical therapies presently available and those projected for future utilization. Dr. Stanley Wallach of the University of South Florida College of Medicine summarized prior experience using porcine calcitonin and the present use of salmon calcitonin. Dr. John Haddad of the University of Pennsylvania School of Medicine provided similar discussion with regard to the use of human calcitonin. Dr. Charles Nagant de Deuxchaisnes of the Catholic University of Louvain, Belgium discussed European experience with new dose forms of calcitonin, especially the nasal spray form that avoids the need for injections. Dr. Frederick Singer of the University of California School of Medicine at Los Angeles discussed the emergence of resistance to calcitonin and the role of antibody formation in the resistant patient.

Several discussants dealt with the use of oral and intravenous bisphosphonates, which are in common use as effective alternatives to calcitonin. Dr. Pierre Meunier of the Faculte Alexis Carrel of the Medical School in Lyon, France discussed his experience with etidronate disodium, the first bisphosphonate to be used as therapy for Paget's disease and the only bisphosphonate available in the United States at present. Dr. Olav Bijvoet of the Medical School at the University of Leiden in The Netherlands discussed his experience using disodium pamidronate, a second generation bisphosphonate. Dr. Peter Burckhardt of Chuv University, Switzerland 
discussed the use of short-term disodium pamidronate treatment and the results to be expected with this newest way of using the bisphosphonates. Dr. John Kanis of the University of Sheffield, England discussed several third generation bisphosphonates undergoing clinical trials in Europe at present.

Finally, Dr. Will Ryan of Rush Presbyterian St. Lukes Medical School in Chicago discussed the present status of plicamycin treatment, a potent antipagetic agent which can be used when neither the calcitonins nor the bisphosphonates are feasible. He also alluded to the newest agent presently in development, gallium nitrate, which was not formally discussed.

This volume and the conference on which it is based have brought the outstanding progress of the last 20 years in treating Paget's disease into present perspective. It also provided much new material that will assist the reader in understanding and applying present research efforts to future therapies. The joint efforts of basic and clinical investigators, the pharmaceutical industry, governmental and voluntary agencies, and of treating physicians are to be recognized for the successes of the past two decades in addressing this previously untreatable disease.

Frederick R. Singer, $M D$

Stanley Wallach, MD 


\section{Acknowledgments}

The editors of this volume wish to extend their sincere thanks to the Paget's Disease Foundation for undertaking the development and management of this fruitful conference, and to the following sponsors for their support of the Symposium: Ciba Geigy Pharmaceuticals, Fujisawa USA-Lyphomed, Merck Sharp and Dohme Research Laboratories, Norwich Eaton Pharmaceuticals, Rhône-Poulenc Rorer, Sandoz Pharmaceuticals, Sanofi Pharmaceuticals, Inc.

The authors are especially indebted to the President of the Board of Directors of the Paget's Disease Foundation, Mr. John B. Johnson, who has been the guiding spirit of the foundation since its inception, and to Mrs. Charlene Waldman, the Executive Director of the Paget's Disease Foundation, who has labored untiringly in the development and management of the conference and has worked yet harder in making this volume a reality.

Special thanks are also due to a number of individuals who were of great importance to the success of the Symposium and this volume. It was the idea of Mr. Walter Oberstebrink, past Chairman of the Paget's Disease Foundation, to sponsor a meeting about the advances in the evaluation and treatment of Paget's disease. Valuable assistance with the preparation of the manuscript was provided by Foundation staff Pamela Champbell 


\section{Xiv ACKNOWLEDGMENTS}

and Barbra Schulman and William Dracos, a Duke University student, who served as a summer intern for the Foundation in 1990.

Finally the herculean efforts of my Co-Editor, Dr. Stanley Wallach, in the editing of many of the chapters of this volume, should be publicly recognized.

Frederick R. Singer, $M D$ 


\section{Foreword to the Annotated Bibliography}

On behalf of the National Arthritis and Musculoskeletal and Skin Diseases Information Clearinghouse (NAMSIC), I am pleased to present a reprint of our publication, Paget's Disease: An Annotated Bibliography.

This annotated bibliography contains 190 citations to patient and professional education materials; most have been published since 1984. Its purpose is to provide information sources for physicians, nurses, other health professionals, and patients and their families regarding the diagnosis, treatment, symptoms, and complications of Paget's disease.

I thank the following individuals for their review of this bibliography: Robert Canfield, MD, Columbia University, New York, New York; Stephen Gordon, PhD, National Institute of Arthritis and Musculoskeletal and Skin Diseases, Bethesda, Maryland; Stephen M. Krane, MD, Massachusetts General Hospital, Boston, Massachusetts; Reva C. Lawrence, MPH, National Institutes of Arthritis and Musculoskeletal and Skin Diseases, Bethesda, Maryland; Frederick R. Singer, MD, Cedars-Sinai Medical Center, Los Angeles, California; Ethel S. Siris, MD, Columbia Presbyterian Hospital, New York, New York; Stanley Wallach, MD, University of South Florida College of Medicine, Tampa, Florida; and especially to Ms. Charlene Waldman, Executive Director, Paget's Disease Foundation, Brooklyn, New York.

The bibliography was prepared by Cheryl Harris, NAMSIC staff, and produced for the Institute under contract No. NO1-DK-2290.

The Clearinghouse selects, acquires, and processes documents and other materials in the areas of patient education, public education, profes- 
sional education, community demonstration programs, and federally funded programs in rheumatic, musculoskeletal, and skin diseases. These materials are available to the public through the Combined Health Information Database (CHID), which can be accessed through the services of a medical librarian or through BRS Information Technology, an online database vendor.

The Clearinghouse also provides a wide range of information dissemination services related to arthritis and musculoskeletal and skin diseases, including responding to public inquiries; publishing a news bulletin, $M E M O$, which is sent to over 9,000 people on the Clearinghouse mailing list; developing bibliographies, fact sheets, and other materials of interest to health professionals and their patients; and distributing professional and patient education materials.

For more information about NAMSIC and our services, please write or call:

National Arthritis and Musculoskeletal and

Skin Diseases Information Clearinghouse

Box AMS

9000 Rockville Pike

Bethesda, Maryland 20892

Telephone: (301) 495-4484

Again, I am honored to be able to contribute to this important text.

Lawrence E. Shulman, MD, PhD

Director, National Institute of Arthritis

and Musculoskeletal and Skin Diseases, National Institutes of Health

Bethesda, Maryland 


\section{Contributors}

\section{Monique Beneton, BSc}

Research Assistant, University of Sheffield Medical School, Beech Hill Road, Sheffield, South Yorkshire, S10 2RX England

\section{Derek Bickerstaff, FRCS}

University of Sheffield Medical School, Beech Hill Road, Sheffield, South Yorkshire S10 2RX England

\section{Olav L. M. Bijvoet, MD}

Professor, University of Leider Medical School, D. Bakkevlaan 61, 2061 EV, Bioemendaal, The Netherlands

\section{Peter Burckhardt, MD}

Chief, Department of Internal Medicine, Chuv University Hospital, 1011 Lausanne, Switzerland

\section{Jean-Pierre Dovogelaer, MD}

Assistant Professor, Department of Rheumatology, Catholic University of Lovain Medical School; St. Luc University Hospital, Avenue Hippocrate 10, B-1200, Brussels, Belgium

\section{Karla Ginger, BS}

Research Assistant, Bone Center, Cedars-Sinai Medical Center, 444 S. San Vicente Boulevard, Los Angeles, California 90048 


\section{XViii CONTRIBUTORS}

\section{John G. Haddad, MD}

Professor and Chief, Endocrinology Section, Department of Medicine, University of Pennsylvania School of Medicine, 611 Clinical Research Building, 422 Curie Boulevard, Philadelphia, Pennsylvania 19104-6149

Neveen A. T. Hamdy, MD

University of Sheffield Medical School, Beech Hill Road, Sheffield, South Yorkshire, S10 2RX England

\section{John A. Kanis, MD}

Reader and Honorary Consultant Physician, Department of Human Metabolism and Clinical Biochemistry, University of Sheffield Medical School, Beech Hill Road, Sheffield, South Yorkshire, S10 2RX England

\section{Frederick S. Kaplan, MD}

Associate Professor of Orthopedic Surgery and Chief, Division of Metabolic Bone Diseases, Departments of Orthopedic Surgery and Medicine, 3400 Spruce Street, Philadelphia, Pennsylvania 19130

\section{Stephen M. Krane, MD}

Persis, Cyrus, and Marlow B. Harrison Professor of Medicine, Harvard Medical School; Chief, Arthritis Unit, Massachusetts General Hospital, Fruit Street, Boston, Massachusetts 02114

Susan F. Kroop, MD

Instructor, Department of Medicine, Harvard Medical School; New England Deaconess Hospital, 185 Pilgrim Road, Boston, Massachusetts 02215

\section{Eugene V. McCloskey, FRCP}

University of Sheffield Medical School, Beech Hill Road, Sheffield, South Yorkshire S10 2RX England

\section{Pierre J. Meunier, MD}

Professor of Medicine, Faculte Alexis Carrel, Rue Guillaume Paradin, 690008 Lyon, France; Director, INSERM Research Unit, Department of Rheumatology and Metabolic Bone Diseases, Edouard Herriot Hospital, Lyon, France

\section{Charles Nagant de Deuxchaisnes, MD}

Professor, Catholic University of Louvain Medical School; Chief, Department of Rheumatology, St. Luc University Hospital, Avenue Hippocrate 10, B-1200 Brussels, Belgium 


\section{Alex Norman, MD}

Professor, Department of Radiology, New York Medical College, Elmwood Hall, Valhalla, New York, 10595

\section{Declan O'Doherty, FRCS}

University of Sheffield Medical School, Beech Hill Road, Sheffield, South Yorkshire, S10 2RX England

\section{Alain Ravault, MD}

Faculte Alexis Carrel, Rue Guillaume Paradin, 690008 Lyon, France

Will G. Ryan, MD

Professor, Department of Medicine, Rush Medical College of Rush University; Director, Osteoporosis Center, Rush Presbyterian-St. Luke's Medical Center, Chicago, Illinois 60612

\section{Frederick R. Singer, MD}

Professor of Medicine in Residence, University of California, Los Angeles, UCLA School of Medicine; Director, Bone Center, Cedars-Sinai Medical Center, 444 S. San Vicente Boulevard, Los Angeles, California 90048

Ethel S. Siris, MD

Associate Professor of Clinical Medicine, Department of Medicine, Columbia University College of Physicians and Surgeons, 630 W. 168 Street, New York, New York 10032

\section{Steven L. Teitelbaum, MD}

Messing Professor of Pathology, Washington University School of Medicine, St. Louis, Missouri; Pathologist-in-Chief, Jewish Hospital at Washington University Medical Center, 216 S. Kings Highway St. Louis, Missouri 63110

Maniccam Thavarajah, PhD

Research Assistant, University of Sheffield Medical School, Beech Hill Road, Sheffield, South Yorkshire S10 2RX, England

\section{Thiébaud, MD}

Department of Internal Medicine, Chuv University Hospital, 1011 Lausanne, Switzerland

\section{Stanley Wallach, MD}

Professor and Associate Chairman, Department of Internal Medicine, University of South Florida College of Medicine, 12901 North 30th Street, Tampa Florida $33612-4799$ 


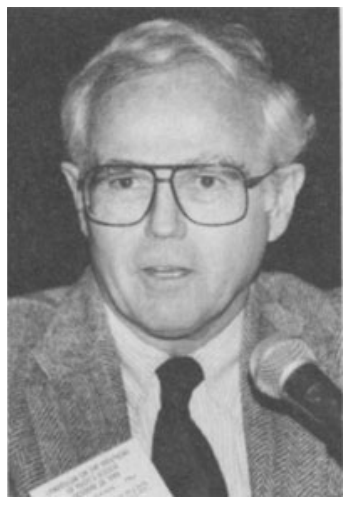

Will G. Ryan

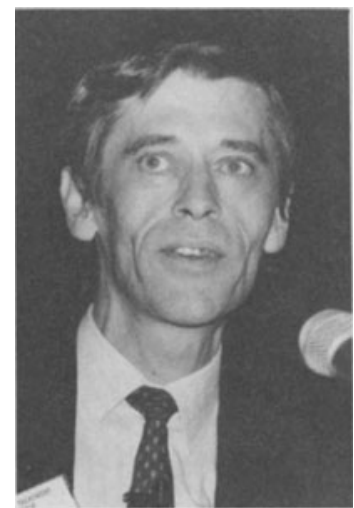

John A. Kanis

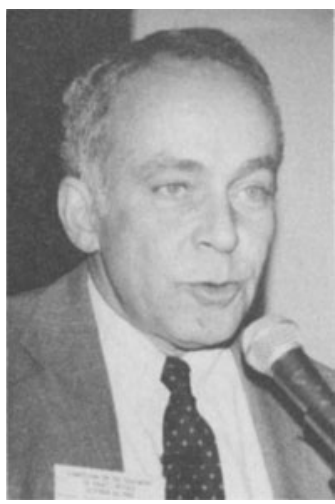

John G. Haddad Jr.

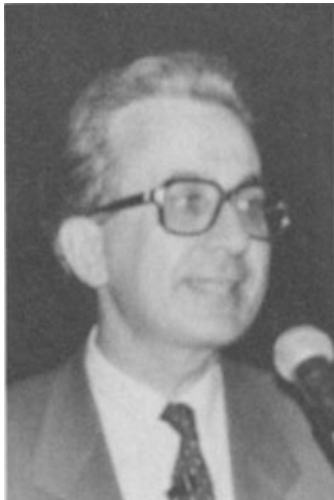

Pierre Meunier

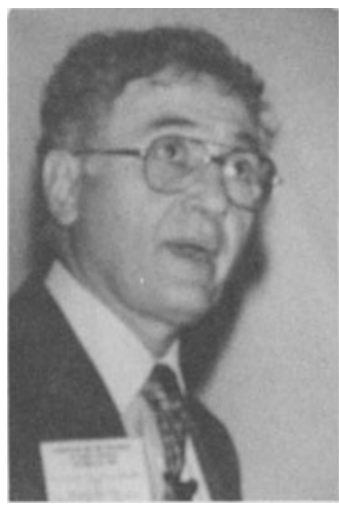

Steven L. Teitelbaum

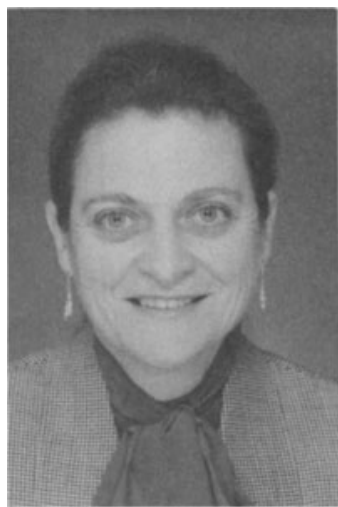

Ethel S. Siris

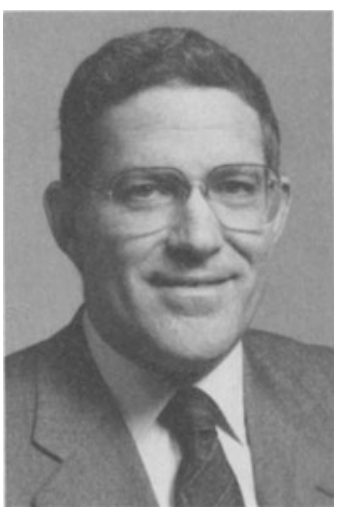

Frederick R. Singer

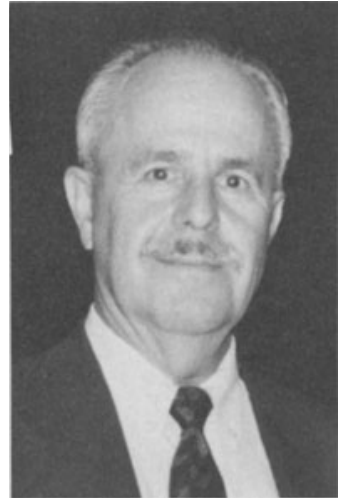

Stanley Wallach 


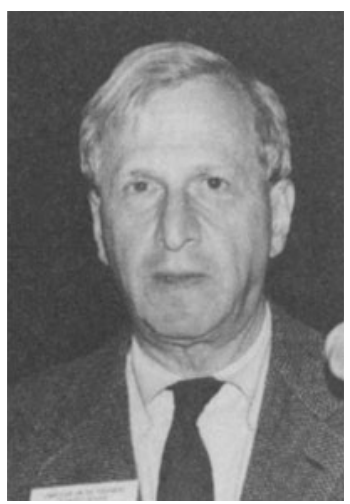

Stephen Krane

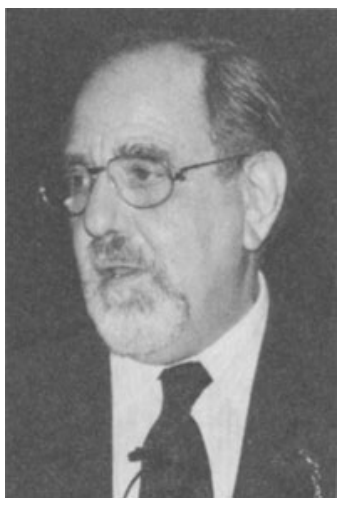

Olav Bijvoet

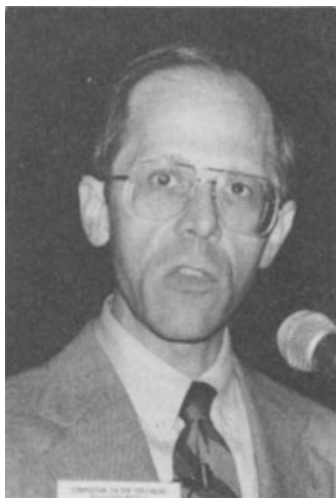

Frederick S. Kaplan

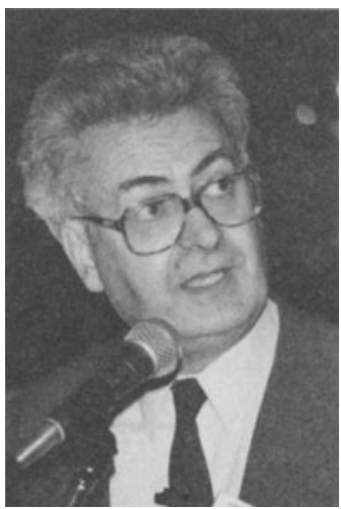

C. Nagant de Deuxchaisnes

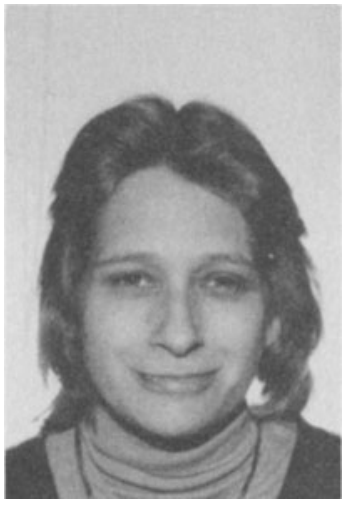

Susan F. Kroop

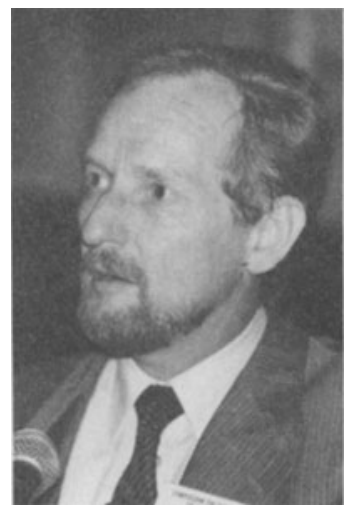

Peter Burckhardt

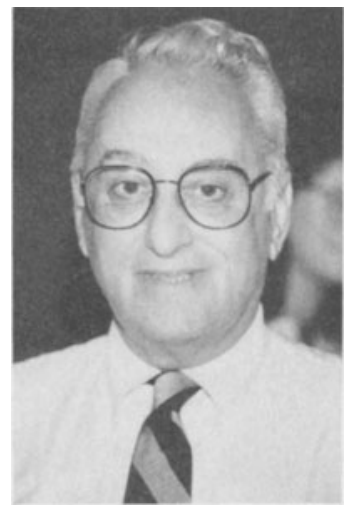

Alex Norman 